\title{
Mortality effects of timing alternatives for hip fracture surgery
}

\author{
Boris Sobolev PhD, Pierre Guy MD, Katie Jane Sheehan PhD, Lisa Kuramoto MSc, Jason M. Sutherland PhD, \\ Adrian R. Levy PhD, James A. Blair MD, Eric Bohm MD, Jason D. Kim MPH, Edward J. Harvey MD, \\ Suzanne N. Morin MD, Lauren Beaupre PhD, Michael Dunbar MD, Susan Jaglal PhD, James Waddell MD; for the \\ Canadian Collaborative Study of Hip Fractures*
}

Cite as: CMAJ 2018 August 7;190:E923-32. doi: 10.1503/cmaj.171512

Visual abstract available at www.cmaj.ca/lookup/suppl/doi:10.1503/cmaj.171512/-/DC2

\begin{abstract}
BACKGROUND: The appropriate timing of hip fracture surgery remains a matter of debate. We sought to estimate the effect of changes in timing policy and the proportion of deaths attributable to surgical delay.
\end{abstract}

METHODS: We obtained discharge abstracts from the Canadian Institute for Health Information for hip fracture surgery in Canada (excluding Quebec) between 2004 and 2012. We estimated the expected population-average risks of inpatient death within 30 days if patients were surgically treated on day of admission, inpatient day 2, day 3 or after day 3. We weighted observations with the inverse propensity score of surgical timing according to confounders selected from a causal diagram.

RESULTS: Of 139119 medically stable patients with hip fracture who were aged 65 years or older, 32120 (23.1\%) underwent surgery on admission day, 60505 (43.5\%) on inpatient day 2, 29236 (21.0\%) on day 3 and 17258 (12.4\%) after day 3. Cumulative 30-day in-hospital mortality was $4.9 \%$ among patients who were surgically treated on admission day, increasing to $6.9 \%$ for surgery done after day 3 . We projected an additional
10.9 (95\% confidence interval $[\mathrm{Cl}] 6.8$ to 15.1) deaths per 1000 surgeries if all surgeries were done after inpatient day 3 instead of admission day. The attributable proportion of deaths for delays beyond inpatient day 2 was $16.5 \%$ (95\% $\mathrm{Cl} 12.0 \%$ to $21.0 \%)$.

INTERPRETATION: Surgery on admission day or the following day was estimated to reduce postoperative mortality among medically stable patients with hip fracture. Hospitals should expedite operating room access for patients whose surgery has already been delayed for nonmedical reasons. n Canada, hospitals admit 30000 older adults with hip fracture annually. ${ }^{1}$ These patients face an increased risk of death, with up to $5 \%$ of women and $10 \%$ of men dying within 30 days. $^{2,3}$ It is generally accepted that early operative intervention improves survival by reducing patients' exposure to immobilization and inflammation. ${ }^{4}$ In 2005, the federal, provincial and territorial governments established a benchmark of 48 hours from admission for $90 \%$ of hip fracture surgeries to prevent potentially harmful delays. ${ }^{5}$ However, delays to hip fracture surgery remain common. ${ }^{6}$ Patients who are medically stable at presentation may have to wait until a surgeon or an operating room becomes available. ${ }^{7,8}$

There has been considerable debate about the point at which delaying hip fracture surgery for nonmedical reasons worsens mortality. ${ }^{9-25}$ This uncertainty leads to prioritization without benefit to the patient or underuse of expeditious surgery that could prevent deaths. Some have argued that understanding the effects of policy change should guide reorganization of operating room resources ${ }^{26}$ and prioritization in the presence of competing demand. ${ }^{7,27-29}$ In this paper, we offer 2 new estimates: the effect of possible changes in surgical timing policy in the same population of patients, and the proportion of in-hospital deaths attributable to surgical delays.

\section{Methods}

\section{Study approach}

Using population-based data, we contrasted the risk of in-hospital death that would be expected (i.e., marginal risk ${ }^{30}$ ) if all patients who are medically stable at presentation were to undergo surgery on the day of admission, on inpatient day 2 , on inpatient day 3 , or after inpatient day 3 . We obtained these risks by stratifying 
observations on confounders identified from an evidence-informed causal diagram, ${ }^{31,32}$ and weighting observations with the inverse propensity score of surgical timing for their respective strata. ${ }^{33} \mathrm{We}$ then combined the weighted observations across strata to construct equal-sized samples, each representing the same patient population treated on a certain day (Appendix 1, available at www. cmaj.ca/lookup/suppl/doi:10.1503/cmaj.171512/-/DC1).

\section{Study population}

The Canadian Institute for Health Information provided discharge abstracts for all patients who underwent hip fracture surgery between Jan. 1, 2004, and Dec. 31, 2012, except for those in Quebec. ${ }^{22}$ We combined multiple abstracts related to transfers to account for time spent at nonsurgical sites. ${ }^{34}$ We excluded patients with conditions that could delay hip fracture surgery; ${ }^{35}$ preoperative intensive care unit admission; more than 9 preoperative days (inconsistent with urgent nature of the procedure); surgery in a hospital with an annual volume of fewer than 24 hip fracture surgeries; or invalid discharge date. We identified abstracts with medical reasons for delay using diagnosis and procedure codes for anemia, anticoagulation, volume depletion, electrolyte imbalance, uncontrolled diabetes, uncontrolled heart failure, acute cardiac arrhythmia or ischemia, acute chest infection or exacerbation of a chronic chest condition. ${ }^{36}$

\section{Outcome}

The outcome was any death within 30 inpatient days after surgery, reported per 1000 surgeries. ${ }^{37}$ The accuracy of in-hospital death data has been validated previously. ${ }^{38}$ We focused on inhospital deaths to isolate the acute phase of hip fracture care, because variation in quality and continuity of care after discharge from hospital may lead to exposure to risk factors that are not related to the timing of surgery. Hospital stays after 30 days were deemed nonacute. ${ }^{39}$

\section{Exposure}

The exposure was the timing of surgery, grouped as the day of admission (reference), on inpatient day 2, on inpatient day 3, and after inpatient day $3 .{ }^{40}$ These groups represent natural timing alternatives, because group membership was governed by the process of booking time in the operating room. After making the decision to operate, surgeons add patients' names to the list of procedures to be carried out within 48 hours, or earlier if the patient has already been delayed by admission late in the day or transfer. ${ }^{7}$ Hospital managers book patients in the order of their addition to the list within the requested urgency category. Most hospitals do not offer evening surgery, and booking may not take place until the next morning if patients arrived after hours). Therefore, booking practices suggest access to surgery is an event occurring on a daily scale, rather than an hourly scale.

\section{Selection of confounders}

We used a causal diagram to select confounders, conditioning on which would be sufficient to render timing and mortality independent. ${ }^{32}$ Figure 1 shows known dependencies among factors that influence the timing of surgery and the occurrence of death, either directly or through a chain of dependencies. ${ }^{48}$ Using Figure 1 , we identified the following factors: treatment era, hospital type, procedure type, age at admission, prefracture health status and surgical readiness (Appendix 1). ${ }^{41,49}$

\section{Stratification}

We constructed $64(=2 \times 2 \times 2 \times 2 \times 4 \times 1)$ multifactor strata on the basis of treatment era (2004-2007, 2008-2012), hospital type (teaching, community), procedure type (fixation, arthroplasty), age at admission (65-84 yr, $\geq 85 \mathrm{yr}$ ) and prefracture health status (admitted from home without comorbidity, admitted from home with comorbidity or with home care services, admitted from a long-term care facility, or admitted from elsewhere) (Supplemental Table 1, Appendix 2, available at www.cmaj.ca/lookup/ suppl/doi:10.1503/cmaj.171512/-/DC1). We considered the following comorbidities: cardiac dysrhythmias, chronic obstructive pulmonary disease, diabetes mellitus, heart failure, hypertension and ischemic heart disease (acute and chronic), identified by diagnostic codes from all hospital discharge abstracts in the year before the index admission. Needham and colleagues ${ }^{50}$ reported substantial agreement between comorbidities in Canadian Institute for Health Information discharge abstracts and hospital charts. Surgical readiness contributed 1 category, because we excluded patients whose discharge abstracts showed medically appropriate reasons for delay.

\section{Statistical analysis}

We estimated cumulative incidence of mortality, accounting for the rate of live discharge. ${ }^{51}$ Postoperative stays were treated as right-censored observations if they exceeded 30 days or if they ended with transfer to another acute care facility or with live discharge within 1 day after the surgery. ${ }^{52}$ We estimated the marginal risk of death as a population average of observations weighted by inverse propensity score of surgical timing, calculated as the proportion of patients with a certain timing of surgery within their respective strata (Appendix 1). We estimated risk differences and odds ratios relative to surgery on the day of admission using the respective marginal risks. ${ }^{53}$ Using the risk estimates for surgery done within 2 inpatient days and for surgery done later, we calculated the proportion of deaths that could be attributed to delaying surgery until after inpatient day 2 , assuming all other contributing factors were distributed as in the study population. ${ }^{49}$ No outcome, exposure or confounder data were missing.

In sensitivity analyses, we compared stratification-based and model-based estimates. ${ }^{54}$ The stratification used fewer categories than available in our data for age, treatment year, comorbidity and hospital type to ensure a sufficient number of events per stratum. The variables for each model were identical to those in the stratification, but the number of categories for each variable corresponded to the observed data. For example, we entered a separate indicator variable for each comorbid condition into regression models. We performed all model-based analyses using the Stata "teffects" package, allowing for intra-hospital correlation among observations. ${ }^{55}$ We used the VanderWeeleArah method to assess whether an unmeasured confounder could explain the risk difference between timing alternatives. ${ }^{56}$ 


\section{Ethics approval}

The University of British Columbia Behavioural Research Ethics Board approved this study.

\section{Results}

\section{Characteristics of the study population}

A total of 195253 discharge abstracts were available for 154389 patients treated at 188 hospitals between 2004 and 2012. After exclusions, the study population consisted of 139119 patients aged 65 years or older who underwent surgery for nonpathologic first-time hip fracture at 38 teaching hospitals and 106 community hospitals (Figure 2). Most of these patients were women (103405[74.3\%]), and almost half were 85 years or older (63786 [45.8\%]). Just more than half the surgeries (72285 [52.0\%]) were done because of a transcervical fracture, and 83643 (60.1\%) involved fixation (Table 1).
Surgical timing was distributed unevenly: 32120 (23.1\%) patients underwent surgery on the day of admission, 60505 (43.5\%) on inpatient day 2, $29236(21.0 \%)$ on day 3 and 17258 $(12.4 \%)$ after day 3 , and surgical timing varied significantly within the strata $(p<0.001$; Supplemental Figure 1, Appendix 2). Patients who underwent surgery soon after admission were less likely to have been admitted from home with comorbidities, were less likely to have been transferred, and were more likely to undergo fixation, with the percentage of patients who were transferred increasing and the percentage of patients with fixation declining as the time to surgery increased (Table 1).

By day 30 after surgery, 6371 (4.6\%) of the patients had died, and 89782 (64.5\%) had been discharged alive. For 17336 (12.5\%) of the patients, the postoperative stay was longer than 30 days, and for $25630(18.4 \%)$, there was another censoring event. The mortality varied across the strata from 11.2 to 138.7 deaths per 1000 surgeries.

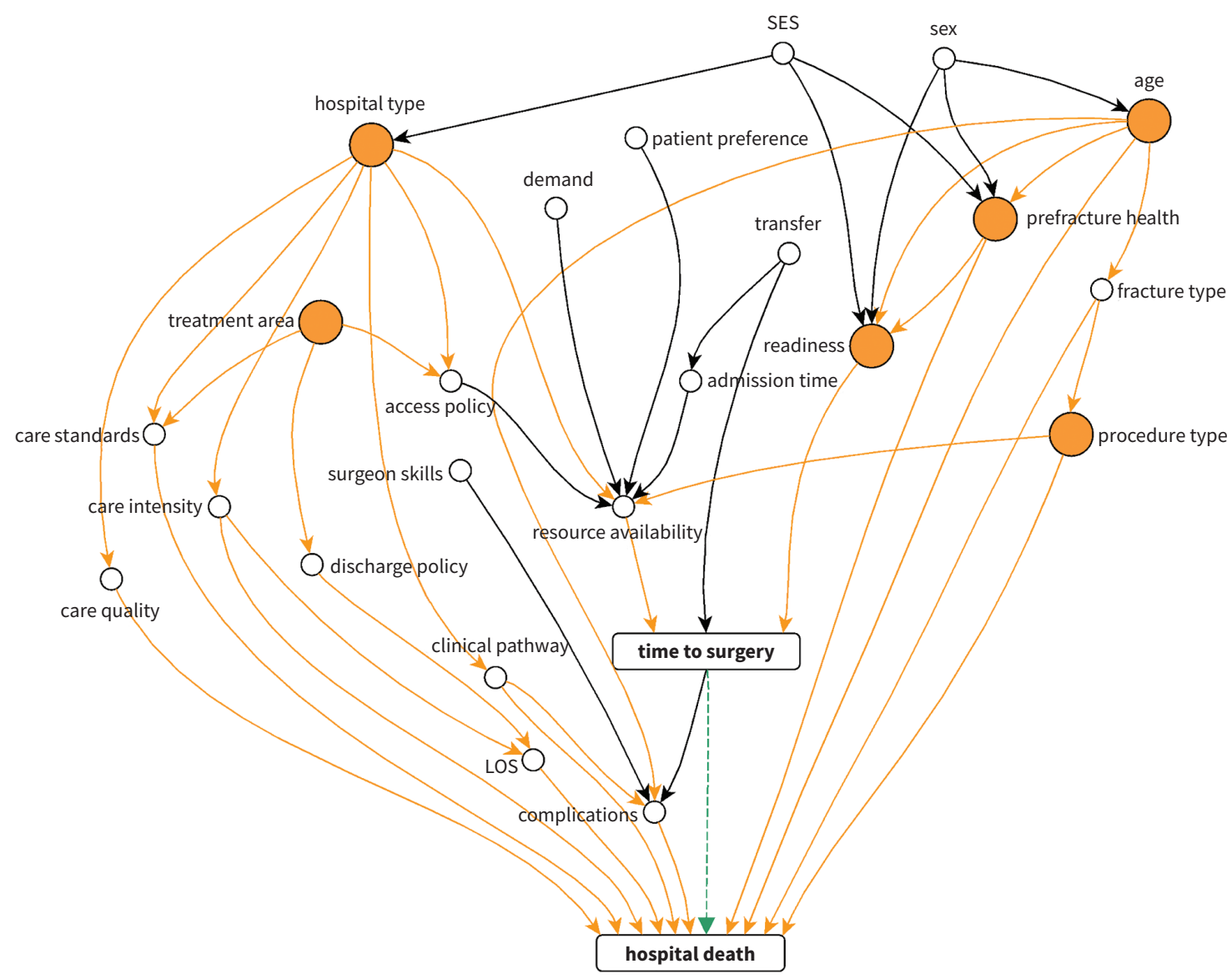

Figure 1: Dependencies among factors involved in producing the association between timing of surgery and in-hospital death after hip fracture. Orange nodes represent the following factors that influence both timing of surgery and occurrence of death through chains of dependencies (orange arrows): treatment era, hospital type, procedure type, age at admission, prefracture health status, and surgical readiness. Conditioning on these factors was sufficient to block all influences that might have produced the putative association between time to surgery and occurrence of death (green dashed arrow) ${ }^{41}$ The dependency graph was adapted from Sheehan and colleagues ${ }^{42}$ to reflect recent publications, adding new nodes (patient preference ${ }^{43}$ and prefracture health status ${ }^{44}$ ) and the following dependencies: between hospital type and socioeconomic status (SES) ${ }^{45}$ between prefracture health and SES, ${ }^{46}$ between resource availability and patient preference, ${ }^{43}$ and between complications and surgeon skills. ${ }^{47}$ Note: LOS $=$ length of stay. 


\section{In-hospital death by timing of surgery}

There were 3903 deaths after 92625 surgeries done on the day of admission or inpatient day 2 (42.1 deaths per 1000 surgeries, 95\% confidence interval [Cl] 40.8 to 43.4), and 2468 deaths after 46494 surgeries done on a later day (53.1 deaths per 1000 surgeries, $95 \% \mathrm{Cl} 51.0$ to 55.1 ). The cumulative 30 -day mortality was 48.9 deaths per 1000 surgeries done on the day of admission and 48.0 deaths per 1000 surgeries done on inpatient day 2 (Figure 3). For surgery carried out later, the mortality was significantly higher: 57.0 deaths per 1000 surgeries done on inpatient day 3 and 69.1 deaths per 1000 surgeries done after inpatient day 3 .

\section{Risk difference for timing alternatives}

Weighting by the inverse propensity score resulted in 4 hypothetical samples of equal size, with identical distribution of the stratification factors but distinct timing of surgery (Figure 4). Table 2 shows the risks of in-hospital death that would be expected if all patients in the study were to undergo surgery on a certain day: $43.3(95 \% \mathrm{Cl} 40.9$ to 45.6$)$ deaths per 1000 surgeries if all were done on the day of admission, $42.6(95 \% \mathrm{Cl} 41.0$ to 44.3$)$ deaths per 1000 surgeries if all were done on inpatient day 2, 49.0 (95\% $\mathrm{Cl} 46.5$ to 51.6$)$ deaths per 1000 surgeries if all were done on inpatient day 3, and $54.2(95 \% \mathrm{Cl} 50.8$ to 57.7$)$ deaths per 1000 surgeries if all were done after inpatient day 3.

Undergoing the procedure on inpatient day 2 rather than the day of admission did not change the risk of death for patients: risk difference $-0.6(95 \% \mathrm{Cl}-3.5$ to 2.2$)$ deaths per 1000 surgeries. However, if all surgeries were done on inpatient day 3 rather than the day of admission, there would be an additional $5.8(95 \% \mathrm{Cl} 2.3$ to 9.2) deaths for every 1000 surgeries, and the number of deaths would increase further, to $10.9(95 \% \mathrm{Cl} 6.8$ to 15.1) deaths for every 1000 surgeries, if all surgeries were done after inpatient day 3 (Table 2).
Relative to surgery on the day of admission, the marginal odds ratios were $0.98(95 \% \mathrm{Cl} 0.92$ to 1.05$)$ for surgery done on inpatient day $2,1.14(95 \% \mathrm{Cl} 1.05$ to 1.23$)$ for surgery on inpatient day 3 , and 1.27 ( $95 \% \mathrm{Cl} 1.16$ to 1.38 ) for surgery after inpatient day 3 (Table 2). The estimates were similar for different specifications of the modelbased analysis (Supplemental Table 3, Appendix 2). Among the 7183 patients who would be expected to die if all surgeries were delayed beyond inpatient day $2,16.5 \%(95 \% \mathrm{Cl} 12.0 \%$ to $21.0 \%)$, or 1221 deaths, could be attributed to not undergoing surgery earlier.

\section{Effect of unmeasured confounding}

We also considered the effects of an unmeasured confounder. For example, evening surgery might be $20 \%$ more prevalent among surgeries done on the day of admission than among those after inpatient day 3, and might increase mortality by, say, 54.2 deaths per 1000 surgeries. The latter figure is artificially high because it equals to the mortality for surgery after inpatient day 3 . This increase implies that mortality almost doubles for evening surgery, if mortality for patients with daytime surgery equals that for operations done on the day of admission; that is, 42 deaths per 1000 surgeries. We calculate that such unmeasured confounding would introduce a bias of $10.8(=54.2 \times 0.2)$ deaths per 1000 surgeries, and therefore our estimate for the risk difference should be reduced to $0(95 \% \mathrm{Cl}-4.1$ to 4.1$)$ deaths per 1000 surgeries. ${ }^{56}$ Alternatively, if evening surgery were to increase the risk of death by 20.9 deaths per 1000 surgeries, then a bias of $4.2(=20.9 \times 0.2)$ would reduce the estimate to $6.7(95 \% \mathrm{Cl} 2.3$ to 10.8$)$ deaths per 1000 surgeries. We therefore conclude that a single unmeasured confounder could produce the observed mortality differences only if it increased the risk of death by a factor of 2 . It seems unlikely that a single unknown factor could have an effect sufficiently large to account, on its own, for the observed difference in mortality between the study groups.

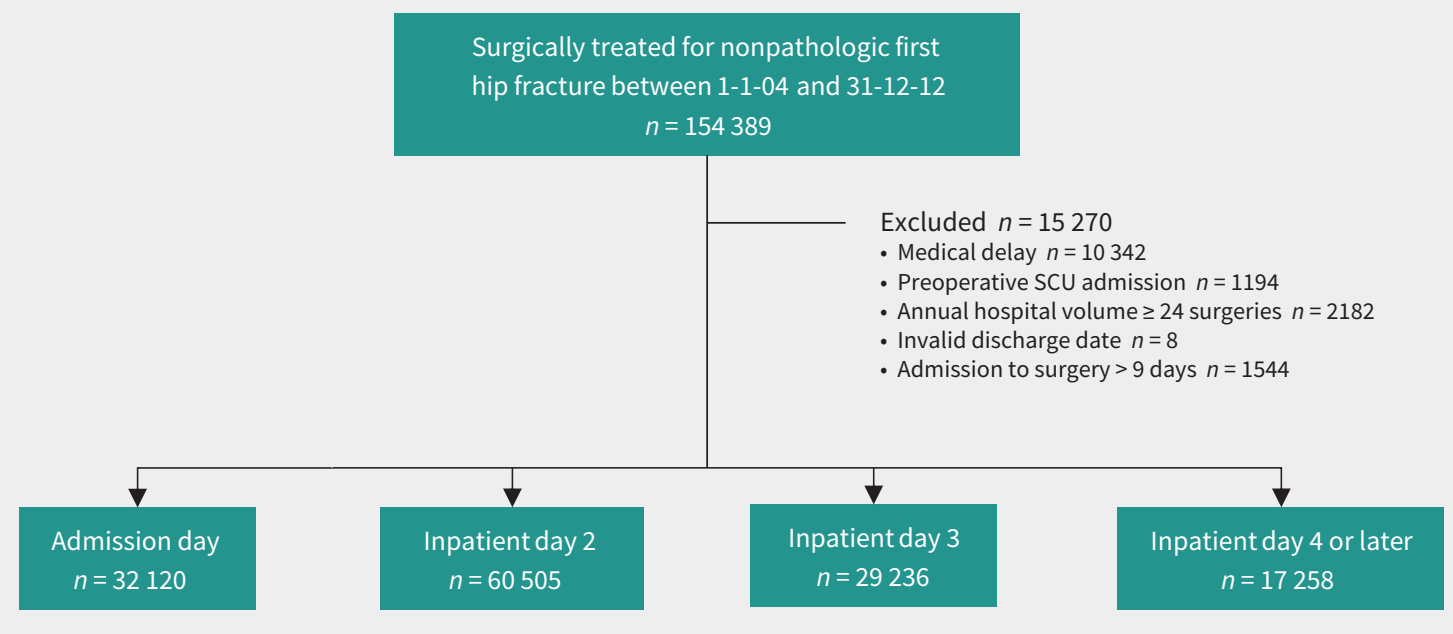

Figure 2: Flow chart for the study population selection. Note: $\mathrm{SCU}=$ special care unit. 
Table 1 (part 1 of 2): Baseline characteristics of patients by timing of surgery

Timing of surgery; no. (\%) of patients

\begin{tabular}{|c|c|c|c|c|c|}
\hline Characteristic & $\begin{array}{l}\text { All patients } \\
n=139119^{\star}\end{array}$ & $\begin{array}{c}\text { Day of admission } \\
n=32120\end{array}$ & $\begin{array}{c}\text { Inpatient day } 2 \\
n=60505\end{array}$ & $\begin{array}{c}\text { Inpatient day } 3 \\
n=29236\end{array}$ & $\begin{array}{c}\text { After } 3 \text { days } \\
n=17258\end{array}$ \\
\hline \multicolumn{6}{|l|}{ Age, yr } \\
\hline $65-74$ & $20827(15.0)$ & $5112(15.9)$ & $8997(14.9)$ & $4223(14.4)$ & $2495(14.5)$ \\
\hline $75-84$ & $54506(39.2)$ & $12499(38.9)$ & 23701 (39.2) & $11475(39.2)$ & $6831(39.6)$ \\
\hline $85-94$ & $56353(40.5)$ & $12743(39.7)$ & $24514(40.5)$ & $12032(41.2)$ & $7064(40.9)$ \\
\hline$\geq 95$ & $7433(5.3)$ & $1766(5.5)$ & $3293(5.4)$ & $1506(5.2)$ & $868(5.0)$ \\
\hline \multicolumn{6}{|l|}{ Gendert } \\
\hline Women & $103405(74.3)$ & $24245(75.5)$ & $45393(75.0)$ & $21480(73.5)$ & $12287(71.2)$ \\
\hline Men & $35699(25.7)$ & $7873(24.5)$ & $15106(25.0)$ & $7754(26.5)$ & $4966(28.8)$ \\
\hline \multicolumn{6}{|l|}{ Prefracture health status } \\
\hline Home without comorbidity & $62291(44.8)$ & $14534(45.2)$ & $27655(45.7)$ & $13024(44.5)$ & $7078(41.0)$ \\
\hline Home with comorbidity $\ddagger$ & $18275(13.1)$ & $3247(10.1)$ & $7048(11.6)$ & $4475(15.3)$ & $3505(20.3)$ \\
\hline Home care & $3295(2.4)$ & $680(2.1)$ & $1521(2.5)$ & $711(2.4)$ & $383(2.2)$ \\
\hline Long-term care facility & $29258(21.0)$ & $6755(21.0)$ & $12816(21.2)$ & $6164(21.1)$ & $3523(20.4)$ \\
\hline Elsewhere & $26000(18.7)$ & $6904(21.5)$ & 11465 (18.9) & $4862(16.6)$ & $2769(16.0)$ \\
\hline \multicolumn{6}{|l|}{ Comorbidity§ } \\
\hline Cardiac dysrhythmias & $11220(8.1)$ & $1823(5.7)$ & $4190(6.9)$ & $2941(10.1)$ & $2266(13.1)$ \\
\hline COPD & $4765(3.4)$ & $993(3.1)$ & $1937(3.2)$ & $1020(3.5)$ & $815(4.7)$ \\
\hline Diabetes mellitus & $4738(3.4)$ & $875(2.7)$ & $1892(3.1)$ & $1092(3.7)$ & $879(5.1)$ \\
\hline Heart failure & $9198(6.6)$ & $1585(4.9)$ & $3359(5.6)$ & $2244(7.7)$ & $2010(11.6)$ \\
\hline Hypertension & $7267(5.2)$ & $1442(4.5)$ & $2976(4.9)$ & $1677(5.7)$ & $1172(6.8)$ \\
\hline $\begin{array}{l}\text { Ischemic heart disease, } \\
\text { acute }\end{array}$ & $6664(4.8)$ & $1267(3.9)$ & $2702(4.5)$ & $1453(5.0)$ & $1242(7.2)$ \\
\hline $\begin{array}{l}\text { Ischemic heart disease, } \\
\text { chronic }\end{array}$ & $1912(1.4)$ & $361(1.1)$ & $695(1.1)$ & $443(1.5)$ & $413(2.4)$ \\
\hline \multicolumn{6}{|l|}{ Hospital type } \\
\hline Teaching & $54212(39.0)$ & $8189(25.5)$ & $23335(38.6)$ & $14182(48.5)$ & $8506(49.3)$ \\
\hline Community large & $63975(46.0)$ & $17078(53.2)$ & $28322(46.8)$ & $11925(40.8)$ & $6650(38.5)$ \\
\hline Community medium & $19513(14.0)$ & $6541(20.4)$ & $8221(13.6)$ & $2875(9.8)$ & $1876(10.9)$ \\
\hline \multicolumn{6}{|l|}{ Annual hospital volume $e^{\star \star}$} \\
\hline Lower for its type & $34231(24.6)$ & $9044(28.2)$ & $14697(24.3)$ & $6712(23.0)$ & $3778(21.9)$ \\
\hline Higher for its type & $104888(75.4)$ & $23076(71.8)$ & $45808(75.7)$ & $22524(77.0)$ & $13480(78.1)$ \\
\hline \multicolumn{6}{|l|}{ Timing of admissiont† } \\
\hline Weekday 12 am to $06: 59 \mathrm{am}$ & $15020(10.8)$ & $6763(21.1)$ & $4969(8.2)$ & $2074(7.1)$ & $1214(7.0)$ \\
\hline Weekday 7 am to $3: 59 \mathrm{pm}$ & $32217(23.2)$ & $10486(32.6)$ & $12681(21.0)$ & $5602(19.2)$ & $3448(20.0)$ \\
\hline Weekday $4 \mathrm{pm}$ to $11: 59 \mathrm{pm}$ & $53039(38.1)$ & $4785(14.9)$ & $25245(41.7)$ & $14864(50.8)$ & $8145(47.2)$ \\
\hline Weekend & $38777(27.9)$ & $10073(31.4)$ & $17591(29.1)$ & $6669(22.8)$ & $4444(25.8)$ \\
\hline \multicolumn{6}{|l|}{ Admission status } \\
\hline Urgent or emergent & $136586(98.2)$ & $31294(97.4)$ & $59440(98.2)$ & $28834(98.6)$ & $17018(98.6)$ \\
\hline Otherwise & $2533(1.8)$ & $826(2.6)$ & $1065(1.8)$ & $402(1.4)$ & $240(1.4)$ \\
\hline \multicolumn{6}{|l|}{ Surgical demandł‡ } \\
\hline Excess demand & $96834(69.6)$ & $22326(69.5)$ & $41724(69.0)$ & $20518(70.2)$ & $12266(71.1)$ \\
\hline Otherwise & $42285(30.4)$ & $9794(30.5)$ & $18781(31.0)$ & $8718(29.8)$ & $4992(28.9)$ \\
\hline
\end{tabular}


Table 1 (part 2 of 2): Baseline characteristics of patients by timing of surgery

\begin{tabular}{|c|c|c|c|c|c|}
\hline \multirow[b]{2}{*}{ Characteristic } & \multirow[b]{2}{*}{$\begin{array}{l}\text { All patients } \\
n=139119^{\star}\end{array}$} & \multicolumn{4}{|c|}{ Timing of surgery; no. (\%) of patients } \\
\hline & & $\begin{array}{c}\text { Day of admission } \\
n=32120\end{array}$ & $\begin{array}{c}\text { Inpatient day } 2 \\
n=60505\end{array}$ & $\begin{array}{c}\text { Inpatient day } 3 \\
n=29236\end{array}$ & $\begin{array}{c}\text { After } 3 \text { days } \\
n=17258\end{array}$ \\
\hline \multicolumn{6}{|l|}{ Transfer history } \\
\hline No & $127812(91.9)$ & $31679(98.6)$ & $57352(94.8)$ & $25660(87.8)$ & $13121(76.0)$ \\
\hline Yes & $11307(8.1)$ & $441(1.4)$ & $3153(5.2)$ & $3576(12.2)$ & $4137(24.0)$ \\
\hline \multicolumn{6}{|l|}{ Preoperative procedures } \\
\hline No & $125297(90.1)$ & 29655 (92.3) & 55225 (91.3) & $25997(88.9)$ & 14420 (83.6) \\
\hline Yes & $13822(9.9)$ & $2465(7.7)$ & $5280(8.7)$ & 3239 (11.1) & $2838(16.4)$ \\
\hline \multicolumn{6}{|l|}{ Fracture type } \\
\hline Transcervical & $72285(52.0)$ & $16075(50.0)$ & $31101(51.4)$ & $15607(53.4)$ & $9502(55.1)$ \\
\hline Inter- or subtrochanteric & $66834(48.0)$ & $16045(50.0)$ & $29404(48.6)$ & $13629(46.6)$ & $7756(44.9)$ \\
\hline \multicolumn{6}{|l|}{ Procedure type } \\
\hline Fixation & $83643(60.1)$ & $20208(62.9)$ & $36908(61.0)$ & $16869(57.7)$ & $9658(56.0)$ \\
\hline Arthroplasty & 55476 (39.9) & $11912(37.1)$ & $23597(39.0)$ & $12367(42.3)$ & $7600(44.0)$ \\
\hline \multicolumn{6}{|l|}{ Year of surgery } \\
\hline 2004-2006 & $46563(33.5)$ & 11476 (35.7) & 20047 (33.1) & $9088(31.1)$ & $5952(34.5)$ \\
\hline 2007-2009 & 45746 (32.9) & $10593(33.0)$ & $19168(31.7)$ & $9713(33.2)$ & $6272(36.3)$ \\
\hline 2010-2012 & $46810(33.6)$ & $10051(31.3)$ & $21290(35.2)$ & $10435(35.7)$ & $5034(29.2)$ \\
\hline \multicolumn{6}{|l|}{ Province } \\
\hline Alberta & $15281(11.0)$ & $3076(9.6)$ & 7008 (11.6) & 3415 (11.7) & $1782(10.3)$ \\
\hline British Columbia & $26774(19.2)$ & $5813(18.1)$ & $12375(20.5)$ & 5830 (19.9) & $2756(16.0)$ \\
\hline Manitoba & $7636(5.5)$ & $1315(4.1)$ & $3673(6.1)$ & $1540(5.3)$ & $1108(6.4)$ \\
\hline New Brunswick & $4774(3.4)$ & $1663(5.2)$ & $1877(3.1)$ & $732(2.5)$ & $502(2.9)$ \\
\hline $\begin{array}{l}\text { Newfoundland and } \\
\text { Labrador }\end{array}$ & $3155(2.3)$ & $748(2.3)$ & $1341(2.2)$ & $717(2.5)$ & $349(2.0)$ \\
\hline Nova Scotia & $5985(4.3)$ & $1917(6.0)$ & $2174(3.6)$ & $1022(3.5)$ & $872(5.1)$ \\
\hline Ontario & $67119(48.2)$ & $16260(50.6)$ & $28390(46.9)$ & $14030(48.0)$ & 8439 (48.9) \\
\hline Prince Edward Island & $1028(0.7)$ & $366(1.1)$ & $363(0.6)$ & $184(0.6)$ & $115(0.7)$ \\
\hline Saskatchewan & $7367(5.3)$ & $962(3.0)$ & $3304(5.5)$ & $1766(6.0)$ & $1335(7.7)$ \\
\hline \multicolumn{6}{|c|}{ 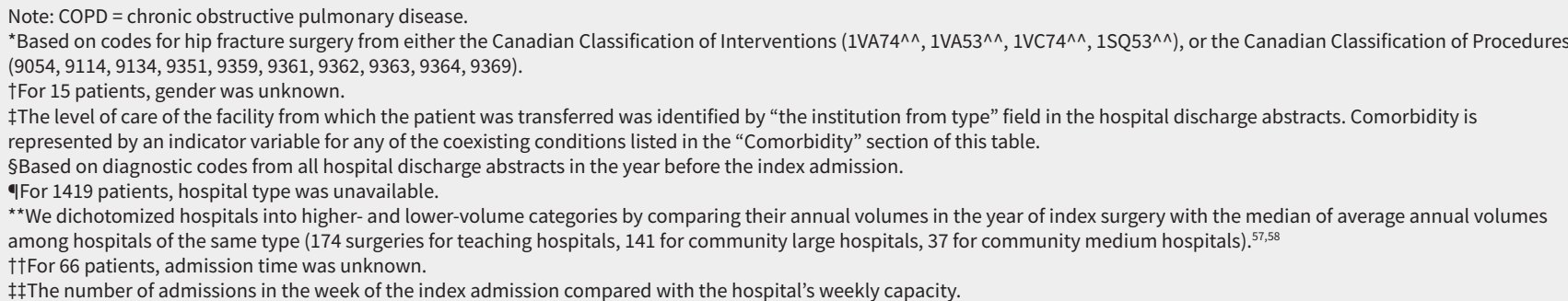 } \\
\hline
\end{tabular}

\section{Interpretation}

We estimated the extent to which in-hospital mortality might change if the timing of hip fracture surgery had been different for a given patient population. We projected an additional 11 deaths for every 1000 surgeries if all patients considered in this study had undergone the operation after waiting 3 days or more, relative to surgery on the day of admission. The proportion of in- hospital deaths attributable to surgical delays beyond inpatient day 2 was estimated at $16.5 \%$.

Lewis and Waddell ${ }^{12}$ concluded that considerable variation in practice and inconsistent evidence leave uncertainty about the optimal timing of hip fracture surgery. Lizaur-Utrilla and colleagues ${ }^{13}$ argued that there is no single timing of hip fracture repair that can be considered optimal for all, because of heterogeneity among patients, their injuries and their care needs. In the 


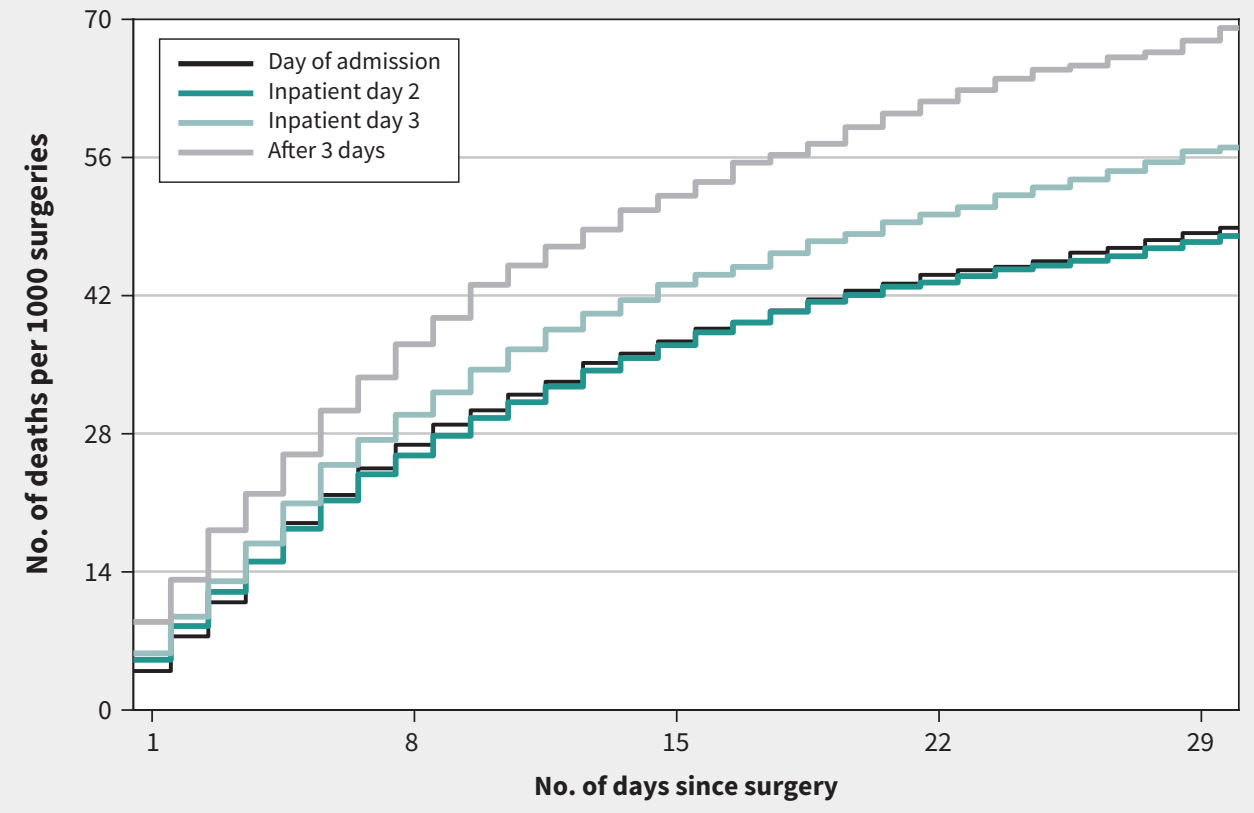

Figure 3: Cumulative incidence of in-hospital death, by observed timing of surgery.

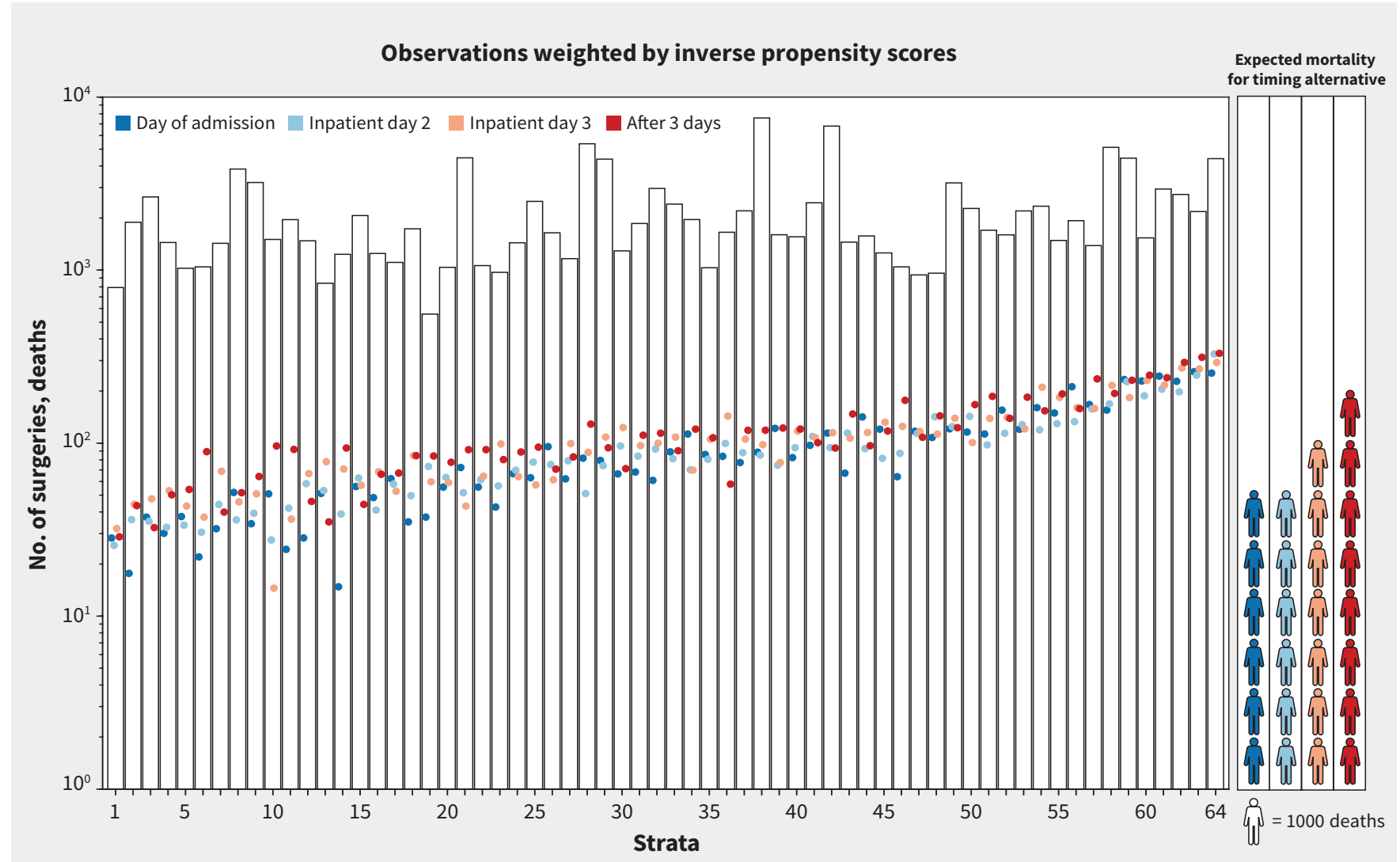

Figure 4: Application of inverse propensity scores of surgical timing to the number observations in various strata. Shown are bars representing the weighted number of surgeries across the 64 multifactor strata. Within each bar, dots show the weighted number of deaths for each timing of surgery. Data are shown on a logarithmic scale to accommodate the range of values. The right panel shows the number of deaths in all strata combined, representing postoperative in-hospital mortality that would be expected if all patients in the study were to undergo surgery on the day of admission, on inpatient day 2, on inpatient day 3, or after inpatient day 3. 
Table 2: Marginal risks, risk differences and odds ratios for timing alternatives

\begin{tabular}{|c|c|c|c|c|}
\hline \multirow[b]{2}{*}{ Measure } & \multicolumn{4}{|c|}{ Timing alternatives, estimate $(95 \% \mathrm{CI})$} \\
\hline & $\begin{array}{c}\text { Day of } \\
\text { admission }\end{array}$ & Inpatient day 2 & Inpatient day 3 & After 3 days \\
\hline $\begin{array}{l}\text { Risk per } 1000 \\
\text { surgeries }^{*}\end{array}$ & $\begin{array}{c}43.3 \\
(40.9 \text { to } 45.6)\end{array}$ & $\begin{array}{c}42.6 \\
\text { (41.0 to } 44.3)\end{array}$ & $\begin{array}{c}49.0 \\
(46.5 \text { to } 51.6)\end{array}$ & $\begin{array}{c}54.2 \\
(50.8 \text { to } 57.7)\end{array}$ \\
\hline $\begin{array}{l}\text { Risk difference per } \\
1000 \text { surgeries }\end{array}$ & Reference & $\begin{array}{c}-0.6 \\
(-3.5 \text { to } 2.2)\end{array}$ & $\begin{array}{c}5.8 \\
\text { (2.3 to } 9.2)\end{array}$ & $\begin{array}{c}10.9 \\
\text { (6.8 to } 15.1)\end{array}$ \\
\hline Odds ratio & 1.00 & $\begin{array}{c}0.98 \\
\text { (0.92 to } 1.05)\end{array}$ & $\begin{array}{c}1.14 \\
\text { (1.05 to } 1.23)\end{array}$ & $\begin{array}{c}1.27 \\
\text { (1.16 to } 1.38)\end{array}$ \\
\hline
\end{tabular}

Note: $\mathrm{Cl}=$ confidence interval.

${ }^{*}$ For each timing alternative, the population-average risk of in-hospital death was estimated by weighting observations with the inverse propensity score of surgical timing within the strata that were defined according to confounders selected from a causal diagram; see Supplemental Table 2 (Appendix 2).

current study, we were concerned with the effect of changes in the timing policy rather than with the etiological question of whether delays worsen mortality. We compared expected mortality for timing alternatives if they had been implemented for the same patient population. Our projections refer to the total effect of the timing alternatives; whether postoperative complications might explain the differences in mortality across these timing alternatives requires further investigation. ${ }^{9}$

Several authors have acknowledged their failure to address imbalance between timing groups in terms of baseline variables that might influence outcomes. ${ }^{31,59-61}$ Therefore, inconsistent findings may result from differences between various surgical timing groups. ${ }^{62}$ We used an evidence-informed causal diagram to justify the selection of variables that would be sufficient to control for a spurious association between timing of surgery and mortality. However, there is still potential for unmeasured confounding, because the causal diagram includes only known factors and dependencies. Although our sensitivity analysis suggested that a single confounding factor could conceivably account for the between-group difference in mortality, such a factor would need to double the risk of postoperative death.

\section{Limitations}

We used administrative data, which might have led to misclassification of medical delays ${ }^{36}$ and underreporting of comorbidity. ${ }^{22}$ In particular, the available data omit renal disease, cerebrovascular accident and dementia, which may influence in-hospital mortality through increased risk of complications. Therefore, some observations in the group "admitted from home without comorbidity" might have been misclassified. However, the percentage of observations in this group was similar across the timing groups, and the percentage of "admitted from home with comorbidity" increased with time to surgery. The study population included only patients who underwent surgery; therefore, our analysis does not account for deaths that occurred before the surgery could be done. ${ }^{63}$

We studied delays that occurred after admission to hospital; data on time between injury and arrival at the hospital and in the emergency department were not available. ${ }^{64}$ It is possible the overall time from injury to surgery, and therefore exposure to immobilization and inflammation, was similar for inpatient day 1 and 2. We were unable to differentiate between surgeries done during and after working hours, because the data on timing of surgery on an hourly basis were not available. Booking surgery to occur after hours would reduce time to surgery, but it might also worsen mortality, because of reduced staffing and surgical team fatigue. Given strategies to address surgical delays that include increasing after-hours surgery, it will be important to study whether this approach produces better outcomes than waiting until the next day.

We did not differentiate between teaching hospitals of various sizes or rural and urban community hospitals; therefore, unobserved variation in care delivery across hospital types might have influenced both the timing of surgery and mortality. Finally, prefracture health status was characterized by a combination of comorbidity and preadmission residence. ${ }^{44}$ Although preadmission residence reflects health care needs, local supply may also influence admission to a long-term care facility. ${ }^{65}$

\section{Conclusion}

Our findings allow for the inference of a critical point for the timing of hip fracture repair. We suggest that all medically stable older adults with hip fracture undergo surgery on the day of their admission to hospital or the following day. This approach places the emphasis of managerial efforts on expediting operating room access for patients whose surgery might be delayed for nonmedical reasons.

\section{References}

1. Leslie WD, O'Donnell S, Jean S, et al.; Osteoporosis Surveillance Expert Working Group. Trends in hip fracture rates in Canada. JAMA 2009;302:883-9.

2. Brauer CA, Coca-Perraillon M, Cutler DM, et al. Incidence and mortality of hip fractures in the United States. JAMA 2009;302:1573-9.

3. Haentjens P, Magaziner J, Colón-Emeric CS, et al. Meta-analysis: excess mortality after hip fracture among older women and men. Ann Intern Med 2010; 152:380-90. 
4. Simunovic N, Devereaux PJ, Sprague S, et al. Effect of early surgery after hip fracture on mortality and complications: systematic review and meta-analysis. CMAJ 2010;182:1609-16.

5. Health indicators 2007. Ottawa: Canadian Institute for Health Information; 2007.

6. Sheehan KJ, Filliter C, Sobolev B, et al.; Canadian Collaborative Study on Hip Fractures. Time to surgery after hip fracture across Canada by timing of admission. Osteoporos Int 2018;29:653-63.

7. Mclsaac DI, Abdulla K, Yang H, et al. Association of delay of urgent or emergency surgery with mortality and use of health care resources: a propensity score-matched observational cohort study. CMAJ 2017;189:E905-12.

8. Orosz GM, Hannan EL, Magaziner J, et al. Hip fracture in the older patient: reasons for delay in hospitalization and timing of surgical repair. J Am Geriatr Soc 2002;50:1336-40.

9. Belmont PJ Jr, Garcia EJ, Romano D, et al. Risk factors for complications and inhospital mortality following hip fractures: a study using the National Trauma Data Bank. Arch Orthop Trauma Surg 2014;134:597-604.

10. Bergeron E, Lavoie A, Moore L, et al. Is the delay to surgery for isolated hip fracture predictive of outcome in efficient systems? J Trauma 2006;60:753-7.

11. Bottle A, Aylin P. Mortality associated with delay in operation after hip fracture: observational study. BMJ 2006;332:947-51

12. Lewis PM, Waddell JP. When is the ideal time to operate on a patient with a fracture of the hip?: A review of the available literature. Bone Joint J 2016;98-B:1573-81.

13. Lizaur-Utrilla A, Martinez-Mendez D, Collados-Maestre I, et al. Early surgery within 2 days for hip fracture is not reliable as healthcare quality indicator. Injury 2016;47:1530-5.

14. Majumdar SR, Beaupre LA, Johnston DW, et al. Lack of association between mortality and timing of surgical fixation in elderly patients with hip fracture: results of a retrospective population-based cohort study. Med Care 2006;44:552-9.

15. Moran CG, Wenn RT, Sikand M, et al. Early mortality after hip fracture: is delay before surgery important? J Bone Joint Surg Am 2005;87:483-9.

16. Orosz GM, Magaziner J, Hannan EL, et al. Association of timing of surgery for hip fracture and patient outcomes. JAMA 2004;291:1738-43.

17. Pincus D, Ravi B, Wasserstein D, et al. Association between wait time and 30-day mortality in adults undergoing hip fracture surgery. JAMA 2017;318:1994-2003.

18. Simunovic N, Devereaux PJ, Bhandari M. Surgery for hip fractures: Does surgical delay affect outcomes? Indian J Orthop 2011;45:27-32.

19. Vidán MT, Sánchez E, Gracia Y, et al. Causes and effects of surgical delay in patients with hip fracture: a cohort study. Ann Intern Med 2011;155:226-33.

20. Weller I, Wai EK, Jaglal S, et al. The effect of hospital type and surgical delay on mortality after surgery for hip fracture. J Bone Joint Surg Br 2005;87:361-6.

21. Management of hip fractures in the elderly: evidence-based clinical practice guideline. Rosemont (IL): American Academy of Orthopaedic Surgeons; 2014.

22. Data quality documentation for external users: Discharge Abstract Database, 20102011. Ottawa: Canadian Institute for Health Information; 2011. Available: www.cihi. ca/en/dad_executive_sum_10_11_en.pdf (accessed 2018 June 20).

23. Hip fracture: care for people with fragility fractures. Toronto: Health Quality Ontario; 2017.

24. Swift C, Ftouh S, Langford P, et al. Interdisciplinary management of hip fracture. Clin Med (Lond) 2016;16:541-4.

25. Scottish Standards of Care for Hip Fracture Patients 2016. The Scottish Government; 2016.

26. Hameed SM, Schuurman N, Razek T, et al.; Research Committee of the Trauma Association of Canada. Access to trauma systems in Canada. J Trauma 2010;69:1350-61.

27. Dexter F, Macario A, Traub RD. Optimal sequencing of urgent surgical cases. $J$ Clin Monit Comput 1999;15:153-62.

28. Mazzocato P, Unbeck M, Elg M, et al. Unpacking the key components of a programme to improve the timeliness of hip-fracture care: a mixed-methods case study. Scand J Trauma Resusc Emerg Med 2015;23:93.
29. Metcalfe D, Olufajo OA, Zogg CK, et al. Are older adults with hip fractures disadvantaged in level 1 trauma centers? Med Care 2016;54:616-22.

30. Austin PC. Absolute risk reductions, relative risks, relative risk reductions, and numbers needed to treat can be obtained from a logistic regression model. J Clin Epidemiol 2010;63:2-6.

31. Agoritsas T, Merglen A, Shah ND, et al. Adjusted analyses in studies addressing therapy and harm: users' guides to the nedical literature. JAMA 2017;317: 748-59.

32. Williamson EJ, Aitken Z, Lawrie J, et al. Introduction to causal diagrams for confounder selection. Respirology 2014;19:303-11.

33. Curtis LH, Hammill BG, Eisenstein EL, et al. Using inverse probability-weighted estimators in comparative effectiveness analyses with observational databases. Med Care 2007;45(Suppl 2):S103-7.

34. Sheehan KJ, Sobolev B, Guy P, et al.; Canadian Collaborative Study on Hip Fractures. Constructing an episode of care from acute hospitalization records for studying effects of timing of hip fracture surgery. J Orthop Res 2016;34:197-204.

35. Hip Fracture Management: Timing of Surgery. London (UK): National Institute for Health and Care Excellence; 2011 (updated May 2017):CG124. Available: www.nice. org.uk/guidance/cg124/chapter/Recommendations\#timing-of-surgery (accessed 2018 June 20)

36. Guy P, Sheehan KJ, Morin SN, et al.; Canadian Collaborative Study on Hip Fractures. Feasibility of using administrative data for identifying medical reasons to delay hip fracture surgery: a Canadian database study. BMJ Open 2017;7:e017869.

37. $A H R Q$ QI ${ }^{T M} I C D-9-C M$ Specification Version 6.0: Inpatient Quality Indicator 19 (IQI 19) hip fracture mortality rate. Rockville (MD): Agency for Healthcare Research and Quality, 2017.

38. Juurlink D, Preyra C, Croxford R, et al. Canadian Institute for Health Information Discharge Abstract Database: a validation study. Toronto: Institute for Clinical Evaluative Sciences; 2006.

39. Kaboli PJ, Go JT, Hockenberry J, et al. Associations between reduced hospital length of stay and 30-day readmission rate and mortality: 14-year experience in 129 Veterans Affairs hospitals. Ann Intern Med 2012;157:837-45.

40. Technical notes for analyses of hip fracture admissions. Ottawa: Canadian Institute for Health Information; 2005. Available: https://secure.cihi.ca/free products/WaitTimesReport_tech_Hip_e.pdf (accessed 2018 June 20).

41. Textor J, Hardt J, Knüppel S. DAGitty: a graphical tool for analyzing causal diagrams. Epidemiology 2011;22:745

42. Sheehan KJ, Sobolev B, Guy P. Mortality by timing of hip fracture surgery: factors and relationships at play. J Bone Joint Surg Am 2017;99:e106.

43. Aggarwal A, Harris IA, Naylor JM. Patient preferences for emergency or planned hip fracture surgery: a cross-sectional study. J Orthop Surg Res 2016; $11: 120$.

44. Health Quality Ontario; Ministry of Health and Long-Term Care. Quality-based procedures: clinical handbook for hip fracture. Toronto: Health Quality Ontario; 2013.

45. Ryan DJ, Yoshihara H, Yoneoka D, et al. Delay in hip fracture surgery: an analysis of patient-specific and hospital-specific risk factors. J Orthop Trauma 2015;29: 343-8.

46. Kristensen PK, Thillemann TM, Pedersen AB, et al. Socioeconomic inequality in clin ical outcome among hip fracture patients: a nationwide cohort study. Osteoporos Int 2017;28:1233-43.

47. Treskes K, Voeten SC, Tol MC, et al. Trauma surgery by general surgeons: Still an option for proximal femoral fractures? Injury 2017;48:339-44.

48. Lohr SL. Sampling: design and analysis. Pacific Grove (CA): Brooks/Cole Publishing Company; 1999:102-3.

49. Pearl J, Glymour M, Jewell NP. Mathematical tool kits for attribution and mediation. In: Causal Inference in Statistics: A Primer. Chinchester (UK): Wiley; 2016:116-9.

50. Needham DM, Scales DC, Laupacis A, et al. A systematic review of the Charlson comorbidity index using Canadian administrative databases: a perspective on risk adjustment in critical care research. J Crit Care 2005;20:12-9. 
51. Sheehan KJ, Sobolev B, Guy P, et al.; Canadian Collaborative Study on Hip Fractures. In-hospital mortality after hip fracture by treatment setting. CMAJ 2016;188:1219-25

52. Austin PC, Lee DS, Fine JP. Introduction to the analysis of survival data in the presence of competing risks. Circulation 2016;133:601-9.

53. Newcombe RG. Interval estimation for the difference between independent proportions: comparison of eleven methods. Stat Med 1998;17:873-90.

54. Schuler MS, Rose S. Targeted maximum likelihood estimation for causal inference in observational studies. Am J Epidemiol 2017;185:65-73.

55. Stata treatment-effects reference manual: potential outcomes/counterfactual outcomes. Release 15. College Station (TX): StataCorp LLC; 2017.

56. VanderWeele TJ, Arah OA. Bias formulas for sensitivity analysis of unmeasured confounding for general outcomes, treatments, and confounders. Epidemiology 2011;22:42-52.

57. Ghaferi AA, Birkmeyer JD, Dimick JB. Hospital volume and failure to rescue with high-risk surgery. Med Care 2011;49:1076-81.

58. Urbach DR, Baxter NN. Does it matter what a hospital is "high volume" for? Specificity of hospital volume-outcome associations for surgical procedures: analysis of administrative data. Qual Saf Health Care 2004;13:379-83.
59. Khan SK, Kalra S, Khanna A, et al. Timing of surgery for hip fractures: a systematic review of 52 published studies involving 291,413 patients. Injury 2009;40:692-7.

60. Leung F, Lau TW, Kwan K, et al. Does timing of surgery matter in fragility hip frac tures? Osteoporos Int 2010;21(Suppl 4):S529-34.

61. Moja L, Piatti A, Pecoraro V, et al. Timing matters in hip fracture surgery: patients operated within 48 hours have better outcomes. A meta-analysis and metaregression of over 190,000 patients. PLoS One 2012;7:e46175.

62. Elwert F. Graphical causal models. In: Morgan SL, editor. Handbook of Causal Analysis for Social Research. Dodrecht (Netherlands): Springer; 2013:245-73.

63. Data quality documentation for external users: Discharge Abstract Database, 2010-2011. Ottawa: Canadian Institute for Health Information; 2011.

64. Bohm E, Loucks L, Wittmeier K, et al. Reduced time to surgery improves mortality and length of stay following hip fracture: results from an intervention study in a Canadian health authority. Can J Surg 2015;58:257-63.

65. Frood J, Johnson T. Improving measures of hip fracture wait times: a focus on Ontario. Healthc Q 2010;13:16-8.

66. Seniors in transition: exploring pathways across the care continuum. Ottawa: Canadian Institute for Health Information; 2017.
Competing interests: Boris Sobolev, Pierre Guy and the Collaborative report receiving grants from the Canadian Institutes of Health Research related to this work. Pierre Guy reports receiving grants from the Natural Sciences and Engineering Research Council of Canada, the Canadian Foundation for Innovation and the British Columbia Specialists Services Committee for work regarding hip fracture care, outside the submitted work. He has also received fees from the BC Specialists Services Committee (for a provincial quality improvement project on redesign of hip fracture care) and from Stryker Orthopaedics (as a product development consultant), outside the submitted work. He is a board member and shareholder in Traumis Surgical Systems Inc. and a board member for the Canadian Orthopaedic Foundation. He also serves on the speakers' bureaus of AOTrauma North America and Stryker Canada. Suzanne Morin reports research grants from Amgen Canada, outside the submitted work. Jason Kim and Lisa Kuramoto report receiving grants from the Canadian Institutes of Health Research, during the conduct of the study. No other competing interests were declared.

This article has been peer reviewed.

Affiliations: School of Population and Public Health (Sobolev, Sutherland, Kim) and Centre for Hip Health and Mobility (Guy), The University of British Columbia, Vancouver, BC; Department of Population Health Sciences
(Sheehan), School of Population Health and Environmental Sciences, King's College London, London, UK; Vancouver Coastal Health Research Institute (Kuramoto), Vancouver, BC; Department of Community Health and Epidemiology (Levy), Dalhousie University, Halifax, NS; Department of Orthopaedics and Rehabilitation (Blair), William Beaumont Army Medical Center, El Paso, Tex.; Section of Orthopaedic Surgery and George and Fay Yee Centre for Healthcare Innovation (Bohm), University of Manitoba, Winnipeg, Man.; Division of Orthopaedic Surgery (Harvey) and Department of Medicine (Morin), McGill University, Montréal, Que.; Departments of Physical Therapy and Division of Orthopaedic Surgery (Beaupre), University of Alberta, Edmonton, Alta.; Division of Orthopaedic Surgery (Dunbar), Dalhousie University, Halifax, NS; Department of Physical Therapy (Jaglal) and Division of Orthopaedic Surgery (Waddell), University of Toronto, Toronto, Ont.

Contributors: All authors contributed to the conception and design of the study. In addition, Boris Sobolev, Pierre Guy, Katie Jane Sheehan, Lisa Kuramoto and Jason Kim contributed to the acquisition and analysis of data. All authors contributed to the interpretation of the data. Boris Sobolev and Lisa Kuramoto drafted the manuscript. All authors revised it critically for important intellectual content, gave final approval of the version to be published and agreed to be accountable for all aspects of the work.
*The Canadian Collaborative Study of Hip Fractures: Lauren Beaupre, Eric Bohm, Michael Dunbar, Donald Griesdale, Pierre Guy, Edward Harvey, Erik Hellsten, Susan Jaglal, Hans Kreder, Lisa Kuramoto, Adrian Levy, Suzanne N. Morin, Katie J. Sheehan, Boris Sobolev, Jason M. Sutherland and James Waddell.

Funding: This research was funded by the Canadian Institutes of Health Research (MOP 133629). This funder has no role in the design of this study, execution, analyses, data interpretation or decision to submit results for publication.

Data sharing: We studied patient records that were anonymized and de-identified by a third party, the Canadian Institute for Health Information, an organization that provides researchers access to data on Canadian residents. Data are available from the Canadian Institute for Health Information for researchers who meet the criteria for access to confidential data.

Acknowledgements: The authors are grateful to Peggy Robinson, ELS, for presubmission manuscript editing, and to Duncan Hunter, Anna Chudyk and Christopher Filliter for useful feedback.

Accepted: June 18, 2018

Correspondence to: Boris Sobolev, boris.sobolev@ubc.ca 